\title{
EXILIO, SUBVERSIÓN Y DIATRIBA EN LA OBRA DE VARGAS VILA Y FERNANDO VALLEJO
}

\author{
POR \\ Fernando Díaz Ruiz \\ Université libre de Bruxelles
}

Una buena parte de la crítica colombiana ha señalado los paralelismos entre las obras y trayectorias de los escritores José María Vargas Vila (1860-1933) y Fernando Vallejo (1942). Expertos en la narrativa del siglo pasado como Luz Mary Giraldo, escritores y columnistas del diario El Tiempo como Óscar Collazos (1942-2015) y Eduardo Escobar (1943) o estudiosos de la novela de finales del siglo XIX y principios del siglo XX como Kevin G. Guerrieri coinciden en encontrar similitudes entre ambos autores. Guerrieri considera a Vallejo como un continuador de la obra de Vargas Vila "en lo que se refiere a su postura iconoclasta y escandalosa, su disidencia y su actitud desacralizante" (307).

En esta misma línea, en un artículo publicado en El Tiempo, a raíz de la entrega del premio Rómulo Gallegos a Vallejo por su novela El desbarrancadero en 2003, Giraldo había incluido a Vallejo junto a Vargas Vila y Porfirio Barba Jacob en "esa línea de autores 'malpensantes' de la sociedad: aquellos que con gusto escandalizan contrariando la historia oficial al revelar verdades 'inconvenientes' o eventos no registrados por la memoria colectiva" ("Visceral"). Cuatro años más tarde, en mayo de 2007, tras la polémica levantada por la renuncia a la nacionalidad colombiana hecha por el autor de La virgen de los sicarios (1994), Óscar Collazos apuntaba en su columna del diario bogotano:

Si la nacionalidad no es más que el vínculo jurídico entre una persona y un Estado, la renuncia de Vallejo rompió apenas un vínculo burocrático y un trámite de fronteras. Dudo de que pueda romper con su memoria cultural. Esta lo vincula para siempre a la fatalidad de ser colombiano y a la tradición de Vargas Vila, Barba Jacob y Fernando González. (“Traición”)

Nuevamente, Vallejo volvía a ser inscrito en una tradición contestataria en la que Collazos añadía al filósofo Fernando González - pocos días después, en un artículo en $E l$ Tiempo titulado "Fernando Vallejo: memoria y conciencia" lo incluía la propia Giraldo, siguiendo lo apuntado con anterioridad por académicas de la talla de María Mercedes 
Jaramillo o escritores como Rafael H. Moreno-Durán (1946-2005)-, ${ }^{1}$ inclusión con la que no se ha mostrado nunca de acuerdo el escritor nadaísta Eduardo Escobar, quien, a pesar de considerar que Vallejo aúna "el estilo pintoresco y desfachatado de Fernando González y el furor antifeminista e iconoclasta de Vargas Vila”, venía criticando desde octubre de 2006 a quienes comparaban a ambos autores:

Algunos comentaristas despistados resolvieron que Fernando Vallejo, el escritor colombiano residenciado en Méjico, es el continuador del escándalo de Fernando González, el maestro envigadeño [...] Vallejo y González llevan el mismo nombre, fueron vecinos hace años, usan en sus obras el habla expresiva de su pueblo [...] suelen ser despiadados con las malicias de este mundo. Pero el escándalo de la obra de Fernando González muestra el desarrollo de un pensamiento y de una personalidad desde su juventud hasta su último texto. [...] Y Vallejo es igual siempre. Si necesita un antecedente, ahí está Vargas Vila. (“Aclaración”)"

Más allá de los repetidos intentos de Escobar por ningunear la obra de Fernando Vallejo, a fin de revalorizar la de Fernando González -filósofo y escritor antioqueño considerado como un maestro por los nadaístas, grupo de poetas a los que Escobar perteneció-, y siendo conscientes de la necesidad de un estudio que analice la relación entre la obra de ambos autores, lo cierto es que todos los críticos, escritores y académicos señalados coinciden en nombrar a Vargas Vila como un antecedente del autor de $E l$ desbarrancadero. Sin embargo, no ha habido muchos estudios que comparen a ambos escritores actualizando la trayectoria y obra de José María Vargas Vila, uno de los autores latinoamericanos más leídos y publicados a principios del siglo XX. Prueba de la vigencia de Vargas Vila en el panorama de referencias literarias en Colombia es el trabajo de Consuelo Triviño, cuya novela La semilla de la ira (2008) lo ha vuelto a presentar a los lectores actuales.

1 Giraldo destacaba el carácter provocador de la obra de González y Vallejo que comparte con Barba Jacob, Vargas Vila y los nadaístas de los años setenta. Bastantes años antes, en "Fernando Vallejo: desacralización y memoria" María Mercedes Jaramillo había señalado estas mismas influencias y algunas otras como Tomás Carrasquilla o El Carnero de Rodríguez Freyle, eso sí, obviando a Vargas Vila. Por otro lado, en 2001 R. H. Moreno Durán también había contado entre la lista de predecesores de Vallejo a Fernando González al igual que al resto de los señalados por Giraldo (más los antioqueños Gregorio Gutiérrez González y Baldomero Sanín Cano), sin mencionar expresamente su filiación con Vargas Vila ("Hasta en las mejores familias").

2 Otro ejemplo de este tipo de ataques se ve en la columna del 19 de octubre de 2009, pocas semanas después de la ceremonia del doctorado Honoris Causa de la Universidad Nacional a Fernando Vallejo (24/09/2009), cuando Escobar escribía "La ira doctorada," un artículo donde al comparar al autor de $E l$ desbarrancadero (2001) con Fernando González, volvía a proclamar la mayor valía e interés de la obra de éste porque tras la misma "se escondía uno que trató de digerir el sufrimiento de vivir para convertirlo en saber".

Revista Iberoamericana, Vol. LXXXI, Núm. 252, Julio-Septiembre 2015, 847-861 ISSN 0034-9631 (Impreso) ISSN 2154-4794 (Electrónico) 
Este artículo tiene por objetivo estudiar los aspectos comunes de las trayectorias de Vargas Vila y Vallejo, el escándalo que acompaña o acompañaba a sus obras y apariciones públicas, y las similitudes de sus textos y pensamiento. Antes de comenzar dicha tarea, parece necesario detenerse a repasar los comentarios de Fernando Vallejo sobre el autor de Ibis (1900), tanto sus declaraciones u observaciones en entrevistas como las efectuadas por el narrador de sus biografías y autoficciones. Comenzando por estas últimas, hay sendas alusiones a Vargas Vila en El río del tiempo $(73 ; 233)$ si bien la primera referencia importante se remonta a 1995 cuando el yo narrador de Almas en pena, chapolas negras. Una biografía de José Asunción Silva, interpela al lector del siguiente modo: “¿Pero por qué ando tan enojado, preguntará usted, como cualquier Vargas Vila jacobino, anticlerical, trasnochado?" (54).

Aun si la referencia a Vargas Vila en este fragmento no deja de ser anecdótica, incluso algo irrespetuosa, y asocie su enojo con el de alguien pasado de moda o "trasnochado", lo cierto es que existe ya una primera autocomparación de sus iras. No será hasta algunos años más tarde, cuando en tres pasajes de El desbarrancadero el yo narrador y personaje vallejiano reconozca de un modo bastante más patente la "influencia maldita" de su paisano modernista, rompiendo incluso una lanza a favor del final de su olvido:

Empiezo a escribir en forma tan arrevesada, cortando a machetazos los párrafos, separando sus frases, por culpa de Vargas Vila, por la influencia maldita de ese escritor colombiano del planeta Marte que escribía en salmodia. (39-40)

$\mathrm{Y}$ al terrible matacuras que hay en mí, descendiente rabioso de los liberales radicales colombianos del siglo XIX como Vargas Vila y Diógenes Arrieta, de la Revolución Francesa, el Marqués de Sade, Renán Voltaire, sectario, hereje, impío ateo, apóstata, blasfemador, jacobino. (179)

¡Ay Vargas Vila, indito feo, rebelde y lujurioso, buen hijo de tu mamá pero apátrida, qué olvidado te tiene la desmemoriada Colombia! Pero si no es ella, ¿quién te va a recordar? (44)

Algunas de estas ideas habían sido ya señaladas por Vallejo en 1998 en un artículo periodístico titulado "Vargas Vila, letras para un viaje" publicado con motivo del lanzamiento por Panamericana de la primera entrega de una colección de obras de José María Vargas Vila. En dicho artículo se habían incluido declaraciones suyas reivindicando su importancia literaria donde destacaba el hecho de que se tratara del "autor en castellano más traducido al francés", así como que "tenía sentido del idioma, de la prosa", eso sí, dejando caer el reproche de que "no tenía el sentido de la autocrítica" ("Vargas Vila, letras para un viaje").

Tras la concesión del premio Rómulo Gallegos a El desbarrancadero en 2003, Vallejo ha sido interrogado en al menos otro par de ocasiones acerca de si se sentía o no heredero de Vargas Vila y parece obvio que el autor de El río del tiempo ha ido acentuando sus

Revista Iberoamericana, Vol. LXXXI, Núm. 252, Julio-Septiembre 2015, 847-861 
diferencias con el autor de El ritmo de la vida (1911) al que ya no reconoce una buena prosa tachándolo de "mal escritor". Además, ahora critica sus errores de ortografía y que sus novelas sean una continua repetición. Eso sí, sigue admitiendo que tiene una gran simpatía por él y valora que pudiera vivir de sus obras en aquellos tiempos, tal y como se observa en apreciaciones hechas en dos entrevistas diferentes, una con el escritor colombiano Héctor Abad Faciolince y otra con el catedrático y periodista Jaime de la Hoz Simanca, colombiano también:

\begin{abstract}
Abad Faciolince: Tu prosa es fascinante por lo suelta, y porque eres un maestro del insulto. Era lo que le reconocía Borges a Vargas Vila. ¿Te sientes heredero de Vargas Vila, de tu tocayo González, de los nadaístas?

Vallejo: Vargas Vila era muy mal escritor pero un gran personaje. Un bellaquito fabulador. El maestro González no sé de quién lo fue, tal vez de los nadaístas. Y éstos, como su nombre lo indica, son nada. (Abad Faciolince)

"No ganaba las fortunas que él [Vargas Vila] decía ni vivía en las villas en las que fechaba sus novelas, al final de ellas -como Villa Ibis, Málaga, que aparece en una de sus obras-, pero podía vivir de lo que escribía. Eso es notable", agrega.

Después, sobrevienen los aguijones: que Vargas Vila escribió veinte novelas que parecían la misma; que era un escritor menor, un prosista malo y de peor gusto; y que, contra lo que parecía, era bastante ignorante [...] (De la Hoz Simanca)
\end{abstract}

\title{
DOS TRAYECTORIAS HERMANADAS: EXILIO Y MALDITISMO IDENTITARIO
}

Diga lo que diga Vallejo, si se deja de lado la calidad de ambas obras y se hace una aproximación a su pensamiento y sus trayectorias vitales y literarias saltan a la vista similitudes evidentes que, eso sí, habrá que ir matizando. Por ejemplo, los dos autores se exiliaron de su país en su juventud con lo que eso supone, Vargas Vila en 1886, a sus veinticinco años (Triviño Anzola, "Anticlericalismo" 61), Fernando Vallejo en 1971, a los veintiocho. Sin embargo, mientras que el autor de Aura o las violetas se vio forzado a hacerlo tras la derrota de los liberales radicales en la batalla de La Humareda frente a las tropas de Rafael Núñez (Vargas Arango 156), la marcha del país de Vallejo se debió más bien a su imposibilidad de poder realizar películas, filmes que Colombia no le ayudaba ni permitía hacer, tal y como recordó el propio escritor en la carta enviada a Caracol Radio para explicar su renuncia a la nacionalidad colombiana en mayo de 2007.

En dicha misiva Vallejo recalcaba el hecho de que su país natal no se conformara con sabotear su filmación, sino que prohibiera la exhibición de la película (realizada finalmente en México en 1977), al considerar que ésta hacía una apología al delito, subrayando que: "Nadie en Colombia, ni una sola persona, levantó su voz para protestar por el atropello, que no era sólo a mí sino al sueño de todos los cineastas colombianos, quienes por lo demás, sea dicho de paso, también guardaron silencio" ("A su estilo").

Revista Iberoamericana, Vol. LXXXI, Núm. 252, Julio-Septiembre 2015, 847-861 ISSN 0034-9631 (Impreso)

ISSN 2154-4794 (Electrónico) 
Lo cierto es que aunque el exilio de ambos autores es de distinta naturaleza-Vargas Vila sólo pudo romperlo en la primavera de 1924, cuando visitó brevemente Barranquilla y fue entrevistado por Rafael Maya (Triviño Anzola, "Anticlericalismo" 69)-, tuvo un desarrollo y unas consecuencias similares, a saber: las obras de ambos fueron prohibidas en Colombia durante algún tiempo, fue de una gran duración (definitivo en Vargas Vila, y si Vallejo no lo remedia, definitivo también) y motivado por el desprecio de ambos hacia sus paisanos, especialmente hacia las clases dirigentes y las masas populares, a las que culpan de los males de su país. Esto último queda claramente de manifiesto en la obra literaria de ambos autores.

No en vano, muchos de los protagonistas o héroes de las novelas más célebres de Vargas Vila son personajes cultos (maestros, poetas o políticos) situados en la Colombia de la Regeneración (1878-1898) de la que él tuvo que huir, y que acaban siendo víctimas de una sociedad de idiotas, bárbaros o envidiosos, de esa "chusma" de la que hablara el narrador de El maestro (33), relato donde el protagonista acabará muriendo apedreado por una multitud que lo siente distinto a ellos, más elevado, y que malinterpreta su bondad hacia su alumno preferido y nieto secreto. A continuación se presentan otros ejemplos de esta relación conflictiva con sus conciudadanos procedentes de dos novelas anteriores, Flor de fango (1898) y Los parias (1902-1903):

Su ciudad natal le había sido hostil. Las pequeñas ciudades como los pequeños países, no perdonan la grandeza exagerada de sus hijos y se vengan proscribiéndolos cuando están en su seno, o fingiendo desconocerlos, si están fuera. (Flor 92)

Su anatema caía en hostiles imprecaciones pasando por sobre los palacios cesáreos, y los capitolios malditos. [...] Y, desafiaba así, el odio de los tiranos insaciables y el odio de las muchedumbres miserables. (Parias 111)

El primer fragmento alude a una reflexión del narrador sobre la protagonista, Luisa, una joven y bella institutriz a la que no se perdona su integridad. La joven se rehúsa a acostarse con un poderoso terrateniente y con un lascivo sacerdote que la acosan (Flor $111-113 ; 228)$, pero es aún más criticado el hecho de que ella hubiera enamorado al hijo del estanciero. El segundo fragmento es parte de uno de los discursos incendiarios del protagonista de Los parias, Claudio Franco, héroe trágico que acabará siendo víctima, al igual que su propia familia, del desdén del pueblo ante una revolución liberal fallida y que es elogiado por el narrador de la novela (235-236) -en las novelas de Vargas Vila el narrador generalmente simpatiza con las ideas defendidas por el autor en sus revistas y panfletos.

Volviendo a Vallejo, como se ha indicado con anterioridad, en todos y cada uno de sus artículos y autoficciones el protagonista y narrador arremete contra el pueblo colombiano, de un modo incluso más injurioso que el utilizado por Vargas Vila:

Revista Iberoamericana, Vol. LXXXI, Núm. 252, Julio-Septiembre 2015, 847-861 ISSN 0034-9631 (Impreso)

ISSN 2154-4794 (Electrónico) 
La Universidad de Antioquia que para el pueblo es gratis, que es del pueblo y para el pueblo, por el pueblo vive en huelga desde hace veinte años. Ni estudian, ni trabajan, ni progresan. Ni dejan estudiar, ni dejan trabajar, ni dejan progresar. Se revuelcan en la mugre incestuosa de sus tugurios, esperando la revolución. Todo se lo roban, todo lo destruyen, todo lo empuercan, y al que algo tiene lo secuestran. (Río 127)

Ay, dizque la clase trabajadora, el pueblo, el proletariado... ¡Cuál clase trabajadora, cuál pueblo, cuál proletariado! ¡Asquerosos! [...] El pueblo es la negación del individuo, que es lo que hay en el aquí y ahora: él, ella, usted, yo... (Rambla 126)

Si se suma a esto lo dicho por Vallejo en sus conferencias y declaraciones, es fácil concluir que hay en ambos autores un desprecio evidente hacia sus paisanos - desprecio recíproco sólo en parte, ya que la recepción de sus obras en Colombia despertó y despierta odios y adhesiones a partes iguales-, un cierto "malditismo literario," en palabras de Bernat Castany Prado, que podría equipararse con el de Juan Goytisolo y que se tiñe de un nihilismo de corte nacional en el caso de Vallejo. ${ }^{3}$

La interesante lectura de Castany Prado de la obra de Fernando Vallejo, hecha a la luz de las tensiones a las que ha sido sometida la identidad de muchos sujetos por la globalización -y construida en función de modelos nacionales-, puede servir de punto de partida para ver el paso hacia delante dado por Vallejo con respecto a Vargas Vila. Así, al situar la obra del autor de El desbarrancadero como ejemplo paradigmático de un "postnacionalismo nihilista", se puede ver cómo a pesar de compartir con su predecesor un "malditismo identitario" que le hace sentirse muy lejos de sus paisanos, Vallejo va más allá en el sentido de que no ve solución futura alguna, al contrario que el editor de Némesis que en última instancia tiene fe en la condición humana y que en obras de corte más político como Los Césares de la decadencia (1907) habla de un presente "inmundo" pero afirma tener esperanza en "el Porvenir" (38). ${ }^{4}$

Sin embargo, a pesar del aparente nihilismo vallejiano que, para ser bien comprendido, debe sumar a su desilusión por la situación de su país natal y el comportamiento de sus conciudadanos el desgarro causado por el paso del tiempo -cuestión que Castany no pasa por alto- ${ }^{5}$ hay en el fondo de su obra una visión hedonista de la vida, un amor

\footnotetext{
3 "Nihilista en cuestiones nacionales sería aquél que se da cuenta de que la nación es una realidad condenada a desaparecer tal y como él la había concebido hasta el momento, pero que no es capaz de sobreponerse a dicha pérdida. Como el Raskólnikov de Dostoievski, que afirmaba 'si Dios ha muerto todo vale', el nihilista pasivo cree que si la nación desaparece él ya no podrá tener una identidad clara y precisa y que todo contrato social está condenado a desaparecer" (Castany Prado).

4 En esta línea optimista, en el prefacio de la edición definitiva de Alba roja señala que "generaciones de hombres en pie, sucederán a las generaciones de cretinos genuflexos" (XIII); hablando de una "iépoca feliz! Que mis ojos no verán..." (XX).

5 "Hay veces en que su nihilismo llega a adquirir una profundidad metafísica, de corte heraclitiano, en la que la disolución nacional no es tanto el resultado de la historia particular de Colombia como de la erosión del tiempo en su sentido más general" (Castany Prado).
}

Revista Iberoamericana, Vol. LXXXI, Núm. 252, Julio-Septiembre 2015, 847-861 ISSN 0034-9631 (Impreso) ISSN 2154-4794 (Electrónico) 
profundo por la existencia y por su patria. De hecho, todo su pesimismo e ira pueden ser vistos como resultado de dicho amor pocas veces correspondido que ha sido puesto de manifiesto en algún caso por el propio autor. Uno de estos ha sido recogido por Luis Ospina en La desazón suprema (2003). Concretamente, me refiero a la escena donde se recoge la respuesta de Vallejo en el programa radiofónico Al aire a la editorial del periodista Germán Santamaría que lo tachaba de resentido y pedía que se prohibiera la exhibición de la película La virgen de los sicarios (2000):

Colombia es el país más asesino de la tierra. Colombia tiene 30.000 asesinatos al año. Y nosotros no podemos tapar el sol con un dedo. No podemos ocultar la verdad. Yo a lo mejor a Colombia la quiero más que ustedes. Y yo no soy un resentido, yo estoy completamente realizado en la vida. (Ospina)

En dicha entrevista un Vallejo cuyo tono no dejaba de recordar al del narrador y personaje de sus autoficciones contaba que él se había realizado completamente para acabar concluyendo: "Y estoy muy triste de no poder vivir en Colombia porque a Colombia la quiero mucho". Más claro no se podía decir. La acusación de ser un resentido, de la que sorprendentemente se ha convertido en vocero académico un crítico de la valía de Pablo Montoya en su más que discutible artículo "Fernando Vallejo, demoliciones de un reaccionario" (2008), hace que se revele al Vallejo vitalista y amante de la vida, sin el cual no hubiera sido posible ni plausible el Vallejo cínico y vociferador de diatribas en autoficciones, ensayos y entrevistas. ${ }^{6}$

Por el contrario, tras la rebeldía e implicación social de Vargas Vila, editor de revistas y panfletos que pretendían alzarse contra las injusticias y la tiranía, defendiendo las libertades y derechos sociales de las clases oprimidas, se halla una visión de la vida como sufrimiento, influenciada por Schopenhauer, donde hay una loa a la soledad y una crítica profunda del amor, que para el Vargas Vila pensador - no para el novelista que hace de éste uno de los motores de sus exitosos folletines- "se impone como yugo o se sufre como servidumbre" (Ritmo 48), cuestión que queda patente en su obra más filosófica, y que se resume mejor en El ritmo de la vida (1911), donde el autor confiesa en una advertencia inicial que la única gloria a la que aspira es "la Ausencia Absoluta del Amor" (VIII) para poco más tarde hacer una elegía de la muerte (6).

${ }_{6}$ En su artículo Montoya confunde y malinterpreta el juego autoficcional de Vallejo, identificando al autor con el narrador y personaje de sus textos y declaraciones a los medios, para acabar tachándolo de seguidor de "un anarquismo de derechas, sesgado por el racismo" (174), haciendo suya la torticera lectura de Eduardo Escobar al apoyar su definición de Vallejo como "un sentimental disfrazado de nazi" (“Aclaración").

Revista Iberoamericana, Vol. LXXXI, Núm. 252, Julio-Septiembre 2015, 847-861 


\section{MAESTROS DE LA DIATRIBA Y DE LA SUBVERSIÓN}

La postura iconoclasta, malpensante y escandalosa de Vallejo y Vargas Vila señalada por la crítica va mucho más allá del malditismo identitario. En mi opinión, estos calificativos se justifican por la evidente carga subversiva de sus obras, artículos y panfletos, textos que van más allá del escándalo provocado por sus diatribas, y que más bien amplifican y anticipan en la mayoría de los casos.

Vargas Vila, por ejemplo, subvierte los valores de una parte importante de la sociedad colombiana de su época (la alta burguesía, la clase terrateniente y el medio rural) al incluir en las páginas de sus libros continuos ataques al clero, escenas de contenido erótico y otras que se alzan contra el matrimonio de conveniencia y el obligado respeto paterno -en un tono mucho más rebelde que el de la célebre María (1867) de Jorge Isaacs donde el protagonista acepta la separación temporal de su amada María impuesta por sus padres e incluso los exime de culpabilidad en la tragedia final.

El anticlericalismo de Vargas Vila fue, sin duda, el aspecto más recurrente y controvertido de su obra. En la mayoría de sus novelas aparece un sacerdote que es presentado como un ser pusilánime -como el clérigo de El Maestro-, mezquino y aliado de los poderosos - es el caso del preceptor de Arturo (209), el joven enamorado de Luisa en Flor de fango-, lascivo y despreciable -tal y como ocurre en la citada Flor de fango con el cura del "pueblo F" (123) que intenta violar a Luisa (187-189)- o hipócrita -como el cura Pérez de Los parias que tiene un hijo (243) violando así los principios de la religión que dice profesar.

Por otro lado, es fácil imaginar las airadas reacciones que pudieron causar novelas de ambientación exótica como La tragedia del Cristo (1914) donde Vargas Vila hace una recreación de la vida de María Magdalena, Judas y Jesucristo en la que éste aparece como un hombre que tiene hermanos y hermanas (178-179) y que mantiene una relación sexual con María Magdalena (190-191). No en vano se habla de la supuesta excomunión de Vargas Vila a raíz del calificativo de "aves negras" para los jesuitas (Vargas Arango 161). También debieron provocar escándalo entre las mentes católicas de la época descripciones como las de la protagonista de Flor de fango contemplándose desnuda frente al espejo (84-87) o la narración de la existencia consentida de relaciones prematrimoniales por parte de los héroes de sus novelas - como Claudio Franco y su

La excomunión es también una aspiración de Vallejo si atendemos a lo que declaró a Edgar Hernández en una entrevista concedida a EFE (2003): "Yo a lo que aspiro es a que el cardenal primado de Colombia me excomulgue, pero no lo logro. Se hacen los desentendidos". Idéntico mensaje al apuntado un año antes por su alter ego y biógrafo en La rambla paralela (2002): "conociéndolo como lo llegué a conocer, lo que sí puedo asegurar es que murió, a ver, ¿cómo decirlo? ¿Frustrado? ¿Amargado? ¿Dolido? ¿Defraudado? ¿Fracasado? El alto honor a que aspiraba no se le dio: que el Cardenal Primado de Colombia lo excomulgara" (98).

Revista Iberoamericana, Vol. LXXXI, Núm. 252, Julio-Septiembre 2015, 847-861 ISSN 0034-9631 (Impreso)

ISSN 2154-4794 (Electrónico) 
prima en Los parias (226) o el profesor separado de El Maestro con Paula Ezpeleta, hija de los dueños de la casa de huéspedes de Villaespino donde se albergaba (17).

La narrativa de Fernando Vallejo es igualmente subversiva y escandalosa para muchos. Así, al profundo anticlericalismo compartido con Vargas Vila, explícito en su ensayo La puta de Babilonia (2007) -lógicamente hoy menos polémico que en los tiempos de La tragedia del Cristo, pero que aún escuece en los sectores conservadores de la sociedad colombiana-, se une el ataque continuo de sus textos a los principales valores morales de su país. ${ }^{8}$ De este modo, se arremete contra la figura de la madre, pilar sagrado de la familia, así como contra la heterosexualidad en cuanto fuente de procreación, reivindicándose una homosexualidad militante en un país donde los defensores de los derechos de este colectivo siguen siendo víctimas de agresiones e incluso homicidios. ${ }^{9}$

La desmitificación de su madre Lía Rendón, llevada al extremo en El desbarrancadero en la que se le apoda "la Loca" en una treintena de ocasiones, resulta más subversiva si cabe porque viene motivada en primera instancia por el reproche que le hace el yo narrador y personaje por haber traído a la vida a tantos hermanos. Es pues un ataque directo a la maternidad, a la figura sacra de la madre, sostén de la familia moderna tras la generalización del divorcio y la proliferación de madres solteras. Este rechazo a las madres ya había sido explicitado por el narrador y personaje de las autoficciones de $E l$ río del tiempo y La virgen de los sicarios al llamar "perras embarazadas" (Río 429) o "putas perras paridoras" (Virgen 92) a las mujeres en estado, alabando las iniciativas de Alfonso Mejía, vecino de enfrente de la finca de Santa Anita en Sabaneta, que comenzó a insultarlas en su vejez (Río 527) o las del loco que presuntamente inyectaba cianuro a las embarazadas en los autobuses de Medellín (Virgen 146). Eso sí, si se tratara de elegir algún pasaje que sintetice el desprecio del narrador vallejiano hacia la maternidad, desprecio que sitúa incluso por encima de su odio hacia la pobrería (Río 679), el más representativo es aquel pronunciado por el narrador tras enterarse de la muerte de su madre en la ficción -la de la real se produjo a finales de mayo de 2007:10

8 En La puta de Babilonia Vallejo se dedica a desvelar las barbaries cometidas por la Iglesia Católica, comenzando por hacer un inventario de los amantes, miserias e intrigas cometidas por los papas, su papel en la persecución y genocidio judío o la falta de autenticidad histórica de Cristo y los textos del Antiguo y Nuevo Testamento, para acabar recogiendo las refutaciones y diatribas lanzadas contra el cristianismo, criticando el lavado de dinero efectuado por la banca vaticana, las encíclicas papales y la exclusión de los animales en su doctrina de amor al prójimo.

9 Véase a este respecto la carta entregada por la asociación Colombia Diversa a la Relatora Especial de las Naciones Unidas durante su visita a Colombia en septiembre de 2009, carta sobre la situación de los defensores de los Derechos Humanos en el país andino que pone de manifiesto las graves conductas homófobas (en forma de homicidios, amenazas y abusos policiales) aún existentes.

10 Véase "Murió la madre del escritor Fernando Vallejo en Medellín".

Revista Iberoamericana, Vol. LXXXI, Núm. 252, Julio-Septiembre 2015, 847-861 ISSN 0034-9631 (Impreso)

ISSN 2154-4794 (Electrónico) 


\begin{abstract}
¡Malditas madres! Primero lo encartan a uno con la existencia y después se mueren, sumándole así a la carga que no pedimos el peso de un dolor que tampoco. ¡Malditas madres! Una madre tiene que morir después que el hijo que parió para que sufra, para que pague, así sólo sea en una diezmillonésima parte, el pecado impagable que cometió. [...] Abogado del derecho a no existir, enemigo empozoñado de las papisas vaticanas y la cópula que preconizan, una sola cosa tengo que decir llegado a este punto para acabar este asunto: por cuarta y última vez: ¡Malditas madres! (Río 639)
\end{abstract}

En cuanto a la segunda de las subversiones comentadas (existen varias más), la vivencia orgullosa de su homosexualidad, constituye otro caballo de batalla de Vallejo, que jamás ha ocultado, tal y como lo viene haciendo el narrador y protagonista de sus autoficciones. Esta insistencia se ve sobre todo desde El fuego secreto (1986), relato de las vivencias homosexuales en la Medellín de su adolescencia a finales de los años cincuenta y principios de los sesenta del siglo pasado. Este hermoso texto, lleno de recuerdos idealizados de una época en que la homosexualidad era vista como una aberración vergonzante y que se vivía en la más absoluta invisibilidad, escandalizó a la sociedad más mojigata de Medellín, pero si lo hizo no fue tanto por desvelar la hipocresía de muchos infelices que vivían una doble vida o por unas descripciones escabrosas que el texto omite, sino por la osadía juvenil con que el protagonista y sus amigos exhiben su feliz vivencia de la homosexualidad:

Escándalo y oprobio de Medellín, rueda el Studebecker cargado de bellezas y cervezas, con alegre complicidad. Un ventarrón de libertad se levanta a su paso. "La cama ambulante" lo ha apodado esta ciudad mendicante de alma ruin, para la que no hay mayor insulto que la felicidad. (Río 206)

Lo más subversivo del segundo relato autoficcional de Vallejo es la desbordante alegría juvenil que la narración logra mantener a pesar de contar los asesinatos homófobos de muchos de sus amigos (185), la tristemente previsible visita del protagonista al loquero (320-323) o el acoso policial que provoca el pánico e intento de huida precipitada de todos los maricas asistentes a una fiesta gay, en un pasaje inolvidable así rememorado: "y yo pensaba en el destino del pueblo elegido: en Moisés y los suyos cruzando por una faja estrecha de tierra el mar Rojo" (Río 249).

Después de haber mostrado algunos aspectos subversivos significativos de las obras de Vargas Vila y Fernando Vallejo, falta analizar los objetivos y motivaciones de dichas subversiones. A lo largo de su tesis sobre Vargas Vila, Consuelo Triviño parece apuntar como uno de sus principales leitmotivs su sed de libertad individual (Sentido trágico 41), una sed absoluta que comparte Vallejo, cuya obra no es en cierto sentido sino una búsqueda imposible de la misma, tal y como declarara su narrador en la sección de Los días azules, parte de El río del tiempo: "Mi vida ha sido siempre una repetida historia: 
me la paso liberándome de mitos, de gentes y de cosas; ahora me libero de mí mismo" (121). Del mismo modo, se pueden citar innumerables ejemplos de cómo el ideal subversivo configura los gustos literarios del yo narrador y personaje vallejiano. ${ }^{11}$ No obstante, es relevante acabar esta reflexión sobre los objetivos compartidos de ambas subversiones con el sugerente análisis de Triviño de las consecuencias finales de la trasgresión vargasvilesca:

Transgredir, profanar, blasfemar, en definitiva, provocar, es lo que busca el héroe vargasvilesco. Sin embargo, al destruir un mito se edifican otros mitos. Negar a Dios con tal vehemencia es, al mismo tiempo confirmar su existencia; pecar deliberadamente es ratificar la existencia de un ser superior, capaz de impartir castigo a los culpables; violar las leyes es desear un castigo por las faltas cometidas. (480; énfasis mío)

De hecho, es evidente que en los dos autores subsiste -detrás de su llamado a la violación de las leyes y de la moral de sus respectivas sociedades- un deseo de ser castigados, una voluntad de orden. En el fondo, el anarquismo de la conducta de ambos en su vida pública, transmitido a sus personajes y en parte proveniente de su afán imposible de libertad, convive con una honda preocupación por la actuación de sus sociedades.

Una vez analizados el carácter subversivo de sus obras (y sin entrar a valorar la desigual calidad de muchas de las de Vargas Vila) resulta innegable que ambos autores deben o debieron buena parte de su popularidad a sus constantes diatribas contra los políticos y autoridades religiosas. Estas han sido o fueron de tal magnitud y calado que en el caso del primero, que las voceó a través de diarios y revistas como Eco Andino, Los Refractarios, El Progreso o Némesis, son las que han provocado (a falta de reediciones de su obra narrativa) que su figura perviva. No sería descabellado afirmar que para muchos críticos Vargas Vila no es sino el autor de aquella célebre injuria sobre Santos Chocano que Jorge Luis Borges consideró como la mejor que conocía, a saber: "Los dioses no consintieron que Santos Chocano deshonrara el patíbulo, muriendo en él. Ahí está vivo, después de haber fatigado la infamia" (Borges I: 422).

El catálogo de injurias de Vargas Vila contra los líderes de la Regeneración colombiana es inagotable, yendo más allá de su obra periodística donde su pluma despotricó sin interrupción contra los políticos de todo el Nuevo Continente, sin olvidar esporádicas críticas a los del Viejo. Libros como Los Césares de la decadencia contienen un recorrido histórico muy personal por la historia de Colombia, plagado de un sinfín de diatribas contra sus presidentes. Por ejemplo, de Miguel Antonio Caro dijo que "para él un adverbio es más importante que un hombre” (70), de José Manuel Marroquín que

${ }^{11}$ Léase su alabanza a Caravaggio cuya luz "desmiente los valores ideales, mentirosos, subvierte la moral pública" (Río 394) o, simplemente, piénsese el inventario de herejes, trasgresores y subversivos que pueblan las páginas de sus escritos, ya sean históricos o ficticios.

Revista Iberoamericana, Vol. LXXXI, Núm. 252, Julio-Septiembre 2015, 847-861 ISSN 0034-9631 (Impreso)

ISSN 2154-4794 (Electrónico) 
"no tuvo ninguna de esas vacilaciones de la Virtud, que a la hora del crimen, asaltan el corazón aun de los hombres más empedernidos en el mal" (90), de Rafael Reyes comentó que "antes de eclipsar a Boves, como Tirano, Reyes, eclipsó la crueldad de Pizarro como Conquistador" (130).

Del mismo modo, Vallejo no se ha mordido la lengua a la hora de criticar a políticos de la importancia de Fidel Castro, Álvaro Uribe, Hugo Chávez, César Gaviria, el rey de España o Andrés Pastrana, tanto en sus entrevistas, conferencias y obras literarias como en los artículos publicados en SOHO de 2005 a 2007. Quizás sea en estos últimos donde las diatribas de Vallejo hayan alcanzado un tono mayor. Así al rey Juan Carlos I lo ha llamado "mujeriego, buen vividor, borrachín y corrupto" ("Bienvenida"), a Hugo Chávez "orangután” y "pitecanthropus erectus" ("Politiquero"), mientras que a Uribe le ha reclamado que se vaya "por politiquero, por desvergonzado, por impúdico, por mentiroso, por demagogo, por blandengue, por inepto, porque no tiene los pantalones bien fajados" ("Por el desafuero").

Señalados algunos ejemplos del uso magistral y reiterado de la diatriba hecha por los dos autores, faltaría analizar sus diferencias en el uso. La lectura atenta de la revista Némesis permite ver que, fuera por convicción o por necesidad de encontrar financiación para sus publicaciones, la pluma de Vargas Vila se pone al servicio del presidente mexicano Álvaro Obregón, al que llega a comparar con José Martí (Némesis 74) y a quien llama en otro artículo "Centinela de la Raza" (Némesis 135), elogios inimaginables para un político en Fernando Vallejo. De este modo, es fácil concluir que aunque ambos hacen de la injuria un arte, sólo el autor de La virgen de los sicarios la usa siempre para trasladar su visión del mundo, una visión que Montoya ha equiparado acertadamente con la cantaleta de su Antioquia natal:

En el caso de Vallejo, la diatriba es una forma elaborada literariamente de lo que en Antioquia se llama cantaleta. Y la cantaleta no es más que un canto [...] que de tanto repetirse y acudir a la invectiva atragantada se convierte en una verbosidad agresiva que hace reír e incomoda las buenas conciencias, pero que también se torna fatigante monotonía. (Montoya 159)

Esta comparación la acompaña Montoya de una advertencia sobre el abuso de este tipo de burla escandalosa que, según él, "corre el riesgo de terminar arrojada al triste rincón de las opiniones difíciles de tomar en serio" (159). En este sentido, como ejemplos de diatribas más vanas y gratuitas se pueden contar las lanzadas por ambos escritores contra el establishment literario, es decir, las críticas de Vargas Vila a Lugones -recreadas por Consuelo Triviño en su novela La semilla de la ira (187-190)- o las de Vallejo o su yo narrador contra Gabriel García Márquez (Díaz Ruiz 46-47) y Octavio Paz-omnipresentes en las tres últimas autoficciones de El río del tiempo-, críticas contra 
la autoridad que no tienen más objeto que el de intentar demoler el canon literario de sus respectivas épocas para inscribirse ellos en el mismo. ${ }^{12}$

En conclusión, el parentesco en el pensamiento entre los dos autores colombianos parece evidente. El propio Fernando Vallejo se ha llegado a reconocer como descendiente del liberalismo radical representado por Vargas Vila. Además, se ha demostrado cómo el origen del carácter subversivo y trasgresor de la obra de ambos responde tanto al descontento con el estado de su país como a una sed absoluta e imposible de libertad individual. También se han podido comprobar las similitudes de sus trayectorias literarias y personales marcadas por el exilio y una vivencia traumática de su relación con sus paisanos, a lo que hay que sumar, en el caso de Vallejo, un profundo desgarro existencial ante el paso del tiempo que conduce inexorablemente a la muerte. Finalmente, al analizar el carácter subversivo de sus obras y la importancia del uso de la diatriba en las mismas, se ha mostrado que a pesar de que en ocasiones, quizás obligado por las circunstancias, Vargas Vila pusiera su pluma al servicio de algunos políticos, también aquí es menos lo que les separa que lo que les une.

\section{OBRAS CITADAS}

"A su estilo, con humor negro, el escritor Fernando Vallejo renuncia a la nacionalidad colombiana". Semana (7 mayo 2007): n. pag. Web. 25 sept. 2013.

Abad Faciolince, Héctor. "Chat con Fernando Vallejo, desde el reino de la muerte". Revista SOHO (5 abril 2004): n. pag. Web. 25 sept. 2013.

Borges, Jorge Luis. Obras completas. 1923 -1949. 4 vols. Barcelona: Emecé Editores, 2004.

Castany Prado, Bernat. "Literatura postnacional en Latinoamérica”. La Habana Elegante Segunda Época 33-34 (2006): n. pag. Web. 25 sept. 2013.

Collazos, Óscar. "Honoris Causa a Vallejo". El Tiempo (24 sept. 2009): n. pag. Web. 25 sept. 2013.

"La traición de Vallejo". El Tiempo (10 mayo 2007): n. pag. Web. 25 sept. 2013.

Colombia Diversa. "Carta a la señora relatora especial sobre la situación de los y las defensores/as de derechos humanos Sra. Margaret Sekaggya de Colombia Diversa”. Bogotá: Colombia Diversa, 2009: n.pag. 25 sept. 2013.<http://colombiadiversa.org/

12 Vallejo ha atribuido estas críticas a su narrador al que define como "un tipo muy extravagante y loco", un personaje para el que "Octavio Paz es un personaje muy antipático por mal escritor y por mal poeta. Se creía que era alguien y ahí no había nadie" (Villena), "La sinceridad". No obstante, basta leer las declaraciones de Vallejo a El Tiempo a la muerte de Paz: "Era un prosista de segunda, un poeta de quinta y un ser humano de décima" -(Sierra), "Vallejo"-, para comprobar hasta qué punto este narrador es indisoluble del Vallejo que ofrece declaraciones y entrevistas a la prensa.

Revista Iberoamericana, Vol. LXXXI, Núm. 252, Julio-Septiembre 2015, 847-861 ISSN 0034-9631 (Impreso)

ISSN 2154-4794 (Electrónico) 
colombiadiversa/images/stories/que/DIVULGACION/RELATORA_ESPECIAL_ SOBRE_LA_SITUACION_DE_LOS_Def_DH.pdf $>$.

Díaz Ruiz, Fernando. "Fernando Vallejo y la estirpe inagotable del escritor maldito".

Caravelle. Cahiers du Monde Hispanique et Luso-Brésilien 89 (2007): 231-48.

"Tras las huellas de Macondo en la Sabaneta de Fernando Vallejo". Gabriel

García Márquez. Un clásico entre dos siglos. J. M. Camacho Delgado y Fernando

Díaz Ruiz, eds. Madrid: Editorial Verbum, 2009. 42-63.

Escobar, Eduardo. “Aclaración impertinente". El Tiempo (31 octubre 2006): n. pag.

Web. 25 sept. 2013.

"La ira doctorada". El Tiempo (19 octubre 2009): n. pag. Web. 25 sept. 2013.

Giraldo, Luz Mary. "Fernando Vallejo: memoria y conciencia". El Tiempo (13 mayo 2007): n. pag. Web. 25 sept. 2013.

“Visceral y contestatario". El Tiempo (6 julio 2003): n. pag. Web. 25 sept. 2013.

Guerrieri, Kevin G. Palabra, poder y nación: la novela moderna en Colombia de 1896 a 1927. Ciudad Juárez: Universidad Autónoma de Ciudad Juárez, 2004.

Hoz Simanca, Jaime de la. "El largo viaje de Fernando Vallejo". Letralia (1 sept. 2008): n. pag. Web. 25 sept. 2013.

Jaramillo, María Mercedes. "Fernando Vallejo: desacralización y memoria”. Literatura y cultura. Narrativa colombiana del siglo XX. María Mercedes Jaramillo, Betty Osorio y A. I. Robledo, comps. Vol. 2. Bogotá: Ministerio de Cultura, 2000.

La desazón suprema: retrato incesante de Fernando Vallejo. Luis Ospina, dir. 2003.

Montoya, Pablo. "Fernando Vallejo, demoliciones de un reaccionario". América: Cahiers du CRICCAL 1/37 (2008): 159-67.

Moreno Durán, Rafael Humberto. "Hasta en las mejores familias". El Tiempo (31 marzo 2001): n. pag. Web. 25 sept. 2013.

"Murió la madre del escritor Fernando Vallejo en Medellín". El Tiempo (1 junio 2007):

n. pag. Web. 25 sept. 2013.

Sierra, Sonia. "Vallejo no escribirá más". El Tiempo (21 junio 1998): n. pag. Web. 25 sept. 2013.

Triviño Anzola, Consuelo. “Anticlericalismo en la generación de fin de siglo: Pompeyo Gener y Vargas Vila”. Fuera del olvido: Los escritores hispanoamericanos frente a 1898. Lourdes Royano, ed. Santander: Servicio de Publicaciones de la Universidad de Cantabria, 2000. 47-80.

El sentido trágico de la vida en la obra de José María Vargas Vila. Madrid:

Editorial de la Universidad Complutense, 1988. La semilla de la ira. Bogotá: Editorial Planeta, 2008.

Vallejo, Fernando. Almas en pena, chapolas negras. Una biografía de José Asunción Silva. Madrid: Editorial Punto de Lectura, 2002.

“Bienvenida al Rey de España”. Revista SOHO (Marzo 2007): n. pag. Web. 25 sept. 2013.

Revista Iberoamericana, Vol. LXXXI, Núm. 252, Julio-Septiembre 2015, 847-861 ISSN 0034-9631 (Impreso) ISSN 2154-4794 (Electrónico) 
El desbarrancadero. Bogotá: Editorial Alfaguara, 2001.

El mensajero. Una biografía de Porfirio Barba Jacob. Bogotá: Editorial

Alfaguara, 2003.

"El politiquero y el primate por Fernando Vallejo." Revista SOHO (Marzo 2005):

n. pag. Web. 25 sept. 2013.

El río del tiempo. Santafé de Bogotá: Editorial Alfaguara, 1999.

La puta de Babilonia. Bogotá: Planeta, 2007.

La Rambla paralela. Madrid: Editorial Alfaguara, 2002.

La Virgen de los sicarios. Madrid: Editorial Punto de Lectura, 2000. Mi hermano el alcalde. Buenos Aires: Editorial Alfaguara, 2004.

"Por el desafuero". Revista SOHO (Enero 2005): n. pag. Web. 25 sept. 2013.

Vargas Arango, M. I. "José María Vargas Vila". Gran Enciclopedia de Colombia. Bogotá:

Círculo de Lectores, 1991. Tomo 4, Literatura, 161-64. Tomo 5, Cultura, 156. Web.

25 sept. 2013. <http://www.lablaa.org/blaavirtual/biografias/vargjose.htm>.

Vargas Vila, José María. Alba roja. Barcelona: Editorial Ramón Sopena, 1919.

Aura o las violetas. 1887. Bogotá: El Pensador Editores, 2000.

El Maestro. Madrid: La Novela Corta, 1917.

El ritmo de la vida. París: Editorial Bouret, 1911.

Flor del fango. París: Editorial Bouret, 1898.

La tragedia del Cristo. París: Librería Americana, 1914.

Los Césares de la decadencia. París: Librería Americana, 1907.

Los parias. Braine-le-Compte, Bélgica: Editorial Bouret, 1902-1903.

Némesis. México: s.n., 1923.

"Vargas Vila, letras para un viaje". El Tiempo (17 mayo 1998): n. pag. Web. 25 sept. 2013.

Villena, Francisco. "La sinceridad puede ser demoledora". Ciberletras 13 (2005). <www. lehman.edu/ciberletras/v13/villenagarrido.htm>. 25 sept. 2013. 
